\title{
Monoclonal antibody induced with inactived EV71-Hn2 virus protects mice against lethal EV71-Hn2 virus infection
}

\author{
Guo-hui Chang*, Yan-jun Luo+, Xiao-yan Wu+, Bing-yin Si+, Lei Lin ${ }^{\dagger}$ and Qing-yu Zhu ${ }^{\dagger}$
}

\begin{abstract}
Background: Enterovirus 71 (EV71) is a viral pathogen that belongs to the Picornaviridae family, EV71-infected children can develop severe neurological complications leading to rapid clinical deterioration and death.

Results: In this study, several monoclonal antibodies (MAbs) were produced by immunizing mice with the inactived EV71 Henan (Hn2) virus strain. The isolated MAbs were characterised by in vitro neutralizing analysis and peptide ELISA. ELISA assay showed that the neutralizing monoclonal antibody 4E8 specifically reacted with synthetic peptides which contain amino acid 240-250 and 250-260 of EV71 VP1. The in vivo protection assay showed that 4E8 can protect twoday-old BALB/C mice against the lethal challenge of EV71 virus.
\end{abstract}

Conclusion: The MAb 4E8 could be a promising candidate to be humanized and used for treatment of EV71 infection.

\section{Background}

Enterovirus 71 (EV71) is a viral pathogen within the Picornaviridae family and causes clinical diseases in humans with manifestations such as herpangina, aseptic meningitis, encephalitis, pulmonary edema and hand, foot and mouth disease (HFMD). EV71-infected children can develop severe neurological complications that lead to rapid clinical deterioration and death [1]. Since the first instances in 1969 [2], several large epidemics of HFMD have been reported in the Asia-Pacific region, especially in Southeast Asia [3-6]. In China, between 1999-2009, HFMD outbreaks caused by EV71 have affected more than 500,000 young children and resulted in more than 200 deaths in cities, such as Beijing, Shenzhen, Guangdong [7-9]. In fact, after the eradication of the poliovirus [10], EV71 has been regarded as the most important neurotropic enterovirus.

Since there is no EV71 vaccine available and treatment is very limited, a humanized monoclonal antibody might

\footnotetext{
*Correspondence: changguohuig99@yahoo.com.cn

1 State Key Laboratory of Pathogen and Biosecurity, Beijing Institute of Microbiology and Epidemiology, 20 Dongda Street, Fengtai District, Beijing, 100071, PR China

+ Contributed equally

Full list of author information is available at the end of the article
}

be a viable treatment option against EV71 infection in humans. Anti-EV71 MAbs which have specificity and neutralizing activity could be a promising candidate to be humanized and used for treatment of EV71 infection.

EV71 contains a positive-stranded RNA enclosed by capsid proteins VP1, VP2, VP3 and VP4. VP1 is composed of 297 amino acids and has been shown to be immunogenic [11]. It has been reported that the synthetic peptides SP55 and SP70, which contain amino acids 163177 and 208-222 of VP1, respectively, can elicit neutralizing antibody against EV71 infection [12,13]. Also, immunization using a recombinant VP1 protein of EV71 was shown to confer protection against lethal EV71 infection in newborn mice, indicating that VP1 contains important antigenic sites that contribute to the neutralization of the virus $[14,15]$.

In this study, we generated several MAbs by immunizing mice with purified EV71 virus, strain Henan2 (Hn2). These MAbs were characterised by in vitro neutralizing analysis and peptide ELISA. We identified a monoclonal antibody, clone 4E8 with strong neutralizing activity against EV71. The MAb 4E8 specifically reacted with synthetic peptides which containing amino acids 240-250 and 250-260 of VP1 by ELISA assay. The in vivo protec- 
tion test showed 4E8 can partialy protect the mice against the lethal challenge of $\mathrm{Hn} 2$ virus.

\section{Results}

$50 \%$ lethal dose $\left(\mathrm{LD}_{50}\right)$ assay

The EV71 Hn2 strain was isolated from the anal swabs of one HFMD patient from Henan province, P.R.China in 2009. Sequence analysis showed the $\mathrm{Hn} 2$ strain was closely related to the EV71 strains detected from the Chinese mainland and grouped into genotype C4 [9]. To determine the $50 \%$ lethal viral dosage, two-day-old $\mathrm{BALB} / \mathrm{c}$ mice were infected intraperitoneally with $100 \mu \mathrm{l}$ of purified $\mathrm{Hn} 2$ virus in dilutions, ranging from 1TCID $_{50}$ (50\% tissue culture infectious dose) to $10000 \mathrm{TCID}_{50}$. All the mice infected with the $1 \mathrm{TCID}_{50}$ and $10 \mathrm{TCID}_{50}$ dilutions survived throughout the 21-day observation period, although during the first week post-infection they had a lower average weight than PBS-inoculated mice (data no shown). With an infective dose of the $100 \mathrm{TCID}_{50}$ dilution and the $1000 \mathrm{TCID}_{50}$ dilution of virus, all of the mice had the typical signs and symptoms of EV71 infection, such as lethargy and paralysis of limbs, within two days postinfection. At the $100 \mathrm{TCID}_{50}$ and $1000 \mathrm{TCID}_{50}$ dilutions respectively, $70 \%$ (7 of 10 ) and 20\% (2 of 10 ) of the mice survived (Fig.1) and lived throughout the 21-day observation period. With the mice infected with the $10000 \mathrm{TCID}_{50}$ dilution of virus, all developed hind-leg paralysis and subsequently died within 9 days post-infection. These results showed that when infected with $100 \mu \mathrm{l}$ of $300 \mathrm{TCID}_{50}$ dilution of stock EV71 Hn2 virus by the intraperitoneal route, $50 \%$ of two-day-old $\mathrm{BALB} / \mathrm{c}$ mice will die within 9 days post-infection.

\section{Neutralizing antibody assay}

After four rounds of panning, seven MAbs were obtained that reacted with high titer in the $\mathrm{Hn} 2$ virus antigencoated ELISA assay. The neutralizing activities of the purified MAbs against EV71 Hn2 virus were analyzed in Vero cells. Two-fold serial dilutions of each MAb were incubated together with $100 \mathrm{TCID}_{50} \mathrm{Hn} 2$ virus and Vero cells, and the cyto-pathic effects (CPE) of cells was observed $72 \mathrm{~h}$ post-infection. A convalescent EV71-infect patient serum was used as a positive control. Among the seven MAbs, three did not have any neutralizing activity, beyond that afforded by a 1:4 dilution of serum from the mock-immunized mice. In contrast, four of the MAbs protected Vero cells from EV71-induced CPE at dilutions ranging from 1:4 to 1:64 (Table 1). The MAbs 4D10 and 3B11 showed a neutralizing activity with complete protection from CPE at dilutions of 1:8 and 1:16, respectively, and the MAbs 4E8 and 4C6 had the same neutralizing titer as the convalescent patient serum, in that they all gave complete protection from EV71-induced CPE at dilutions up to 1:64.

\section{Identification of monoclonal antibody epitopes by peptide-coated ELISA}

The epitope-specificity of all four neutralizing monoclonal antibodies was tested by peptide-coated ELISA. Synthetic peptides and E.coli expressed EV71 VP1 were coated onto the 96-well microtiter plates. Inactived, purified $\mathrm{Hn} 2$ virus was used as a positive control. The results showed that all of the neutralizing monoclonal antibodies gave a strong positive signal with inactived $\mathrm{Hn} 2$ virus antigen. Among these positive monoclonal antibodies, only 4E8 and 4C6 were strongly reactive with the E.coli expressed VP1 protein. MAbs 4E8 and 4C6 also specifically reacted with synthetic VP1 peptides P25 (aa240250) and P26 (aa250-260)(Table 2). MAb 4C6 showed a weaker reactivity to the synthetic peptides when compared with $4 \mathrm{E} 8$.

\section{Amino acid sequence analysis of EV71 Hn2 VP1}

The antigenicity of the EV71 Hn2 VP1 protein was determined using the method of Kolaskar and Tongaonkar [16]. Antigenic peptides were predicted based on the occurrence of amino acid residues in experimentally known segmental epitopes. This analysis indicated that there were seven predicted antigenic determinants in the Hn2 VP1 sequence. One of the predicted antigen epitopes (aa242-251: KSKYPLVVRI) was located at the Cterminus of the Hn2 VP1 and corresponded to the synthetic peptide P25 (aa240-250). Sequence alignment indicated that the amino acid sequence of peptide P25 (aa240-250) was less well conserved when compared to the amino acid sequence represented by peptide P26 (aa250-260), which was totally conserved amongst the 19 EV71 strains from sub-genogroups A to C4 (Fig. 2).

\section{Passive protection test in mice}

Two-day-old BALB/c mice were inoculated with the EV71 $\mathrm{Hn} 2$ virus at a dose of $100 \mathrm{LD}_{50}$ per mouse by the intraperitoneal $(100 \mu \mathrm{l})$ route. Then, $24 \mathrm{~h}$ later, they were given $100 \mu \mathrm{l}$ of MAb 4E8 at different dilutions (1:4, 1:8, $1: 16,1: 32,1: 64)$. The results showed that control mice that were administered with 4E8 (1:4) antibody remained healthy and survived throughout the 21-day observation period. The Hn2 inoculated groups that were administered with normal mouse serum had the typical symptoms of EV71 infections by day two post-inoculation and, by day 8 post-inoculation, all the mice had developed hind leg paralysis and subsequently died. In contrast $69 \%$ of the Hn2 inoculated mice that were administered with a 1:4 dilution of MAb 4E8 survived throughout the 21-day observation period; The mice administered with 1:8 and 1:16 dilution 4E8 were less protected but, nevertheless 


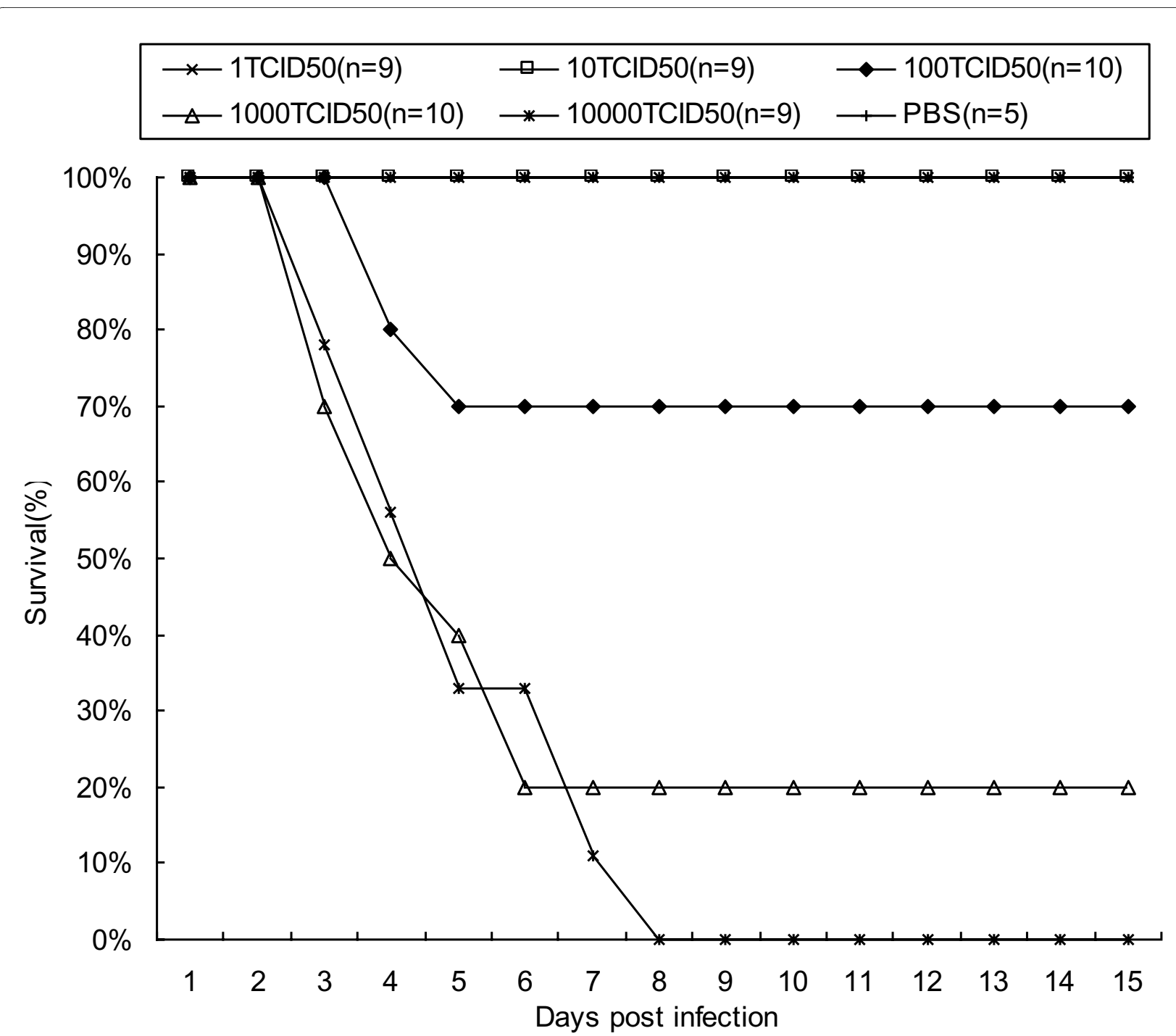

Figure $1 \mathbf{5 0} \%$ lethal dose $\left(\mathbf{L D}_{\mathbf{5 0}}\right)$ assay. Two-day-old BALB/c mice were infected intraperitoneally with $100 \mu \mathrm{l}$ of purified $\mathrm{Hn} 2$ virus in dilutions, ranging from $1 \mathrm{TCID}_{50}$ to $10000 \mathrm{TCI} \mathrm{D}_{50}$. The survival rates were observed for 21 days.

$46 \%$ and $22 \%$, respectively, survived. Though the inoculated mice administered with a 1:32 dilution $4 \mathrm{E} 8$ began to die a little later than mice administered with normal mouse serum, they all died within 10 days. Similar to the inoculated mice administered with normal mouse serum, all of the inoculated mice administered with 1:64 dilution 4E8 died within 7 days (Fig. 3).

\section{Discussion}

The genus Enterovirus, belongs to the family Picornaviridae, and consists of 66 different subtypes, including polioviruses (PVs), coxsackievirus group A (CVA) and coxsackievirus group $\mathrm{B}(\mathrm{CVB})$, echoviruses, and enteroviruses [17,18]. EV-71 was first described in 1969 during an outbreak of HFMD in California that was associated with central nervous system (CNS) complications. EV71 infections are generally mild, such as HFMD and herpangina, but occasionally lead to severe diseases with CNS involvement and clinical symptoms such as aseptic meningitis, poliomyelitis-like paralysis and possibly fatal encephalitis in neonates [19]. Passive transfer of specific antibodies has been shown to reduce the severity of viral infections, including Japanese encephalitis infection [20], varicella infection [21] and coxsackievirus infection [22]. High-quality MAbs which have specificity, avidity and neutralizing activity might be a viable treatment option for EV71 infection in humans.

Previous studies have shown the neutralizing epitope of EV71 was mainly located at the VP1 protein. So we selected synthetic VP1 peptides as the antigen to screen a 
Table 1: In vitro neutralization assays of monoclonal antibodies*

\begin{tabular}{cc}
\hline Antibodies & Neutralization titers \\
\hline Convalscent patient serum & $1: 64$ \\
$4 \mathrm{D} 10$ & $1: 8$ \\
$3 \mathrm{~B} 11$ & $1: 16$ \\
$4 \mathrm{E} 8$ & $1: 64$ \\
$4 \mathrm{C} 6$ & $1: 64$ \\
$4 \mathrm{G} 9$ & $<1: 4$ \\
1A5 & $<1: 4$ \\
$2 \mathrm{~F} 7$ & $<1: 4$ \\
Normal mouse serum & $<1: 4$
\end{tabular}

*50 $\mu$ l of virus suspension containing $100 T \mathrm{TCI}_{50}$ EV71 Hn2 was pre-incubated with $50 \mu \mathrm{l}$ of serial two-fold dilutions of antibodies for $30 \mathrm{~min}$ before adding to Vero cells in 96 -well plates. After 3 days at $37^{\circ} \mathrm{C}$, the titer of neutralizing antibody was read as the highest dilution that gave complete protection from CPE.

set of MAbs that we had generated by immunization with inactived EV71 isolated strain Hn2. Among the MAbs we characterised, four were shown to have neutralizing activity, and two can react specifically with the E.coli expressed VP1 protein and synthetic peptides of VP1. Experiments are currently in progress to see if the neutralizing MAbs that do not react with VP1 may neutralize the virus by alternative routes, for example, by preventing uncoating of the virus by binding to neighbouring capsid pentamers or by forming aggregates of the viruses as has been observed in other picornaviruses [23,24].

Computerized antigenicity prediction method as used in this study can predict antigenic determinants with about $75 \%$ accuracy. Four of the seven epitopes predicted by this method in the EV71 VP1 protein are located at the $\mathrm{N}$-terminus, and only one at the $\mathrm{C}$-terminus. This result is consistent with reports that show the region spanning

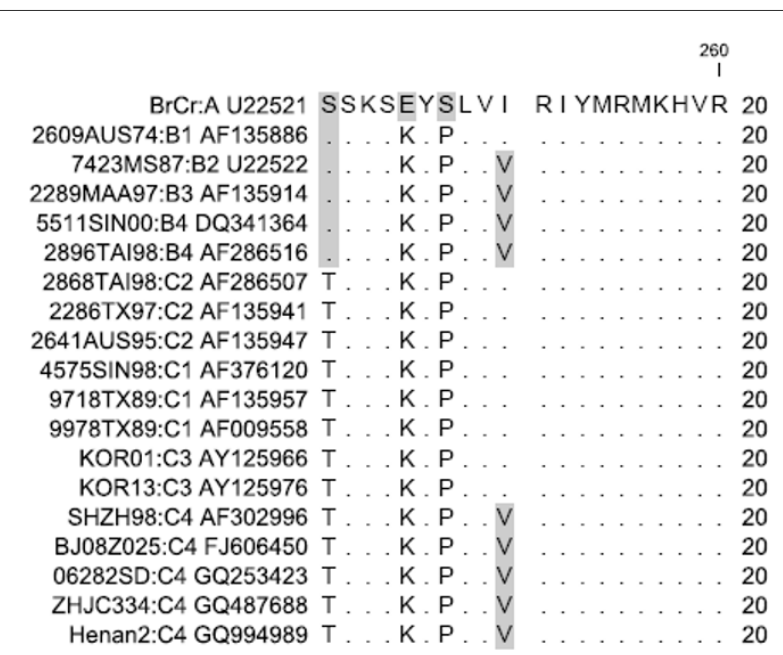

Figure 2 Sequence alignment of aa240-260 of EV71 VP1 using CLC Main Workbench 5.5 software. Identical residues with the standard strain $\mathrm{BrCr}$ are indicated as dots. Amino acids that differ from the consensus sequence (i.e. the majority of amino acids at a position) are shaded.

amino acids 66-132 of VP1 contains the major dimerization domain and cross-reactive enterovirus epitopes [25]. However, there are also reports show that the region between amino acids 132 and 297 is indispensable, and contains important conformational epitope which can react with the convalescent-phase sera [26]. In this study, we have shown that the MAbs 4C6 and 4E8 can specifically react with peptides P25(aa240-250) and P26(aa250260), one of which overlaps with the predicted C-terminus epitope. Whether the two peptides form a conformational epitope or just a linear neutralizing epitope requires futher research. Nevertheless, it is important that we have shown the $4 \mathrm{E} 8 \mathrm{MAb}$ was able to protect suckling BALB/c mice from a lethal dose of EV71 Hn2 virus, and, therefore, could be a promising candidate to be humanized and used for treatment of EV71 infection.

Table 2: Epitope-specificity assay of monoclonal antibody by ELISA*

\begin{tabular}{|c|c|c|c|c|}
\hline Antibody & Expressed VP1 & Hn2 virus & PBS & Peptide \\
\hline $4 \mathrm{D} 10$ & 0.400 & 2.551 & 0.056 & - \\
\hline $3 B 11$ & 0.338 & 1.740 & 0.072 & - \\
\hline 4E8 & 1.820 & 2.665 & 0.034 & $\begin{array}{l}1.374 \text { (P25:aa240-250) } \\
1.448 \text { (P26:aa250-260) }\end{array}$ \\
\hline \multirow[t]{2}{*}{$4 C 6$} & 1.727 & 2.774 & 0.080 & 0.705 (P25:aa240-250) \\
\hline & & & & 0.488 (P26:aa250-260) \\
\hline Normal mouse serum & 0.113 & 0.611 & 0.045 & 0.072 \\
\hline
\end{tabular}

*The 96-well microtiter plates were coated with $500 \mathrm{ng}$ of purified EV71 Hn2 virus, E.coli expressed VP1 protein or synthetic VP1 peptide P25 or P26. Monoclonal antibodies were at a dilution of 1:2000. $\mathrm{OD}_{450} \mathrm{~nm}$ readings are expressed as the average of of three separate experiments. 


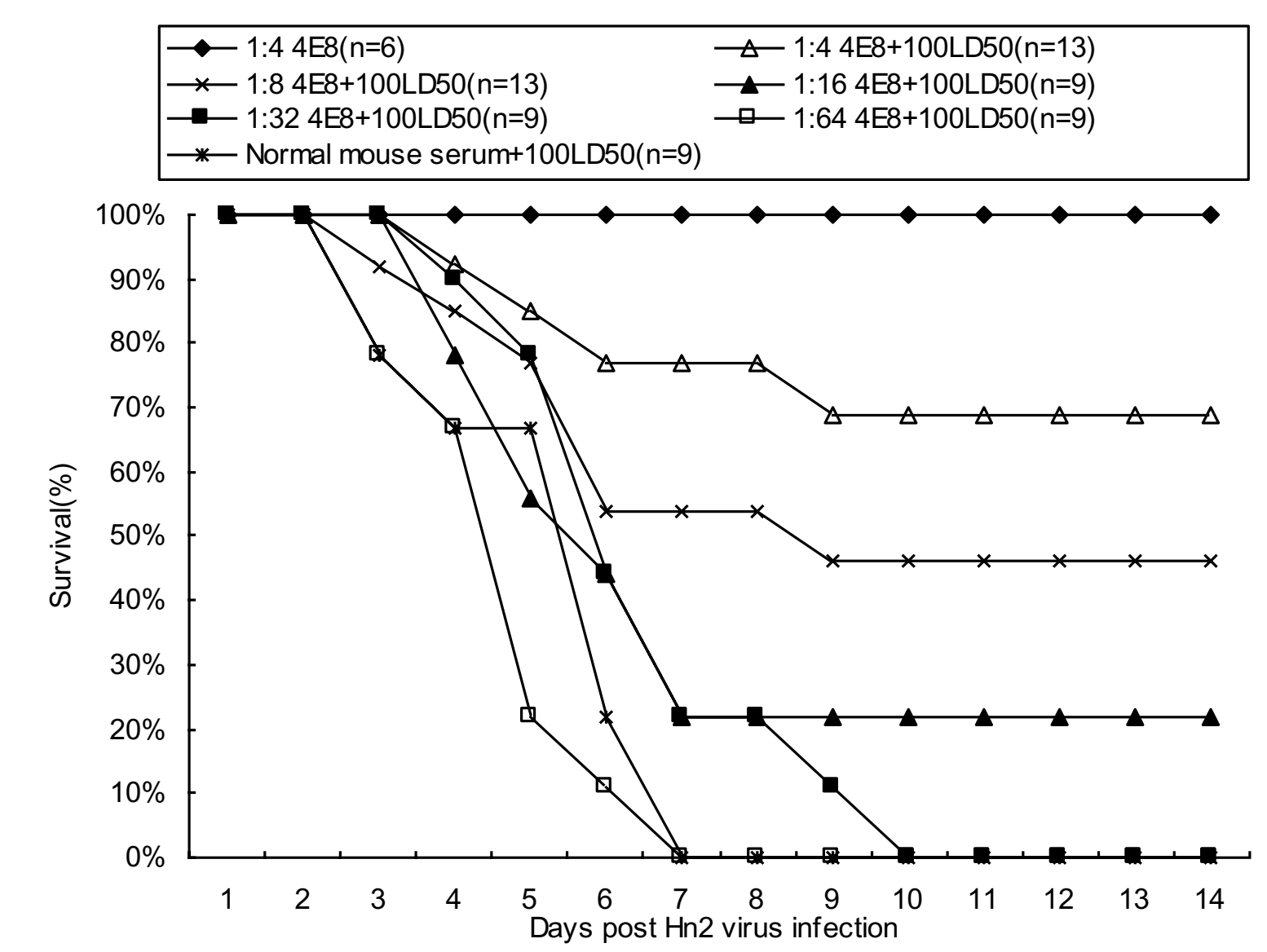

Figure $\mathbf{3}$ In vivo passive protection assay. Groups of two-day-old BALB/c mice were inoculated with EV71 Hn2 virus (100 LD 50 per mouse) via the intraperitoneal route. Then, $24 \mathrm{~h}$ after infection, they were intraperitoneally administered with serially diluted 4E8 monoclonal antibody. Mice in control groups were administered with normal mice serum, death was monitored until 21 days postinfection.

\section{Conclusion}

In this study, we generated a set of MAbs by immunization BALB/c mice with inactived EV71 isolated strain Hn2. Among the MAbs we characterised, four were shown to have neutralizing activity, and two can react specifically with the E.coli expressed VP1 protein and synthetic peptides P25(aa240-250) and P26(aa250-260) of VP1. It is important that we have shown the 4E8 MAb was able to protect suckling BALB/c mice from a lethal dose of EV71 Hn2 virus, and, therefore, could be a promising candidate to be humanized and used for treatment of EV71 infection.

\section{Materials and methods \\ Cells and viruses}

Rhabdomyosarcoma cells (RD cell) and Vero cells (derived from African green monkey kidney) were maintained in Dulbecco's modified Eagle's medium (DMEM) containing $10 \%$ fetal bovine serum (FBS) plus $2 \mathrm{mM} \mathrm{L-}$ glutamine, $100 \mathrm{U}$ of penicillin, and $100 \mu \mathrm{g}$ of streptomycin per ml. The EV71 Hn2 strain was isolated from the anal swabs of one HFMD patient from Henan province, P.R.China in 2009. The patient had the typical clinical symptoms of central nervous system (CNS) involvement, such as fever, exanthemas, aseptic meningitis, and stiffness of the neck [2]. The Hn2 strain was C4 genotype and the complete sequence of $\mathrm{Hn} 2$ was submitted to GenBank as accession no. GQ994992.

\section{Virus purification and titer determination}

The isolated Hn2 virus were purified by three rounds of plaque assay in RD cells, then propagated in Vero cells. The infected cells were harvested and completely lysed by three cycles of freeze-thaw. The virus from the tissue culture was purified by precipitation with $7 \%$ polyethylene glycol 8000 and then centrifuged onto a 30\% sucrose cushion at 25,000 $\mathrm{g}$ for $4 \mathrm{~h}$. Virus titers were determined as the median end-point of the tissue culture infectious dose $\left(\mathrm{TCID}_{50}\right)$. Serially diluted virus samples (from $10^{-2}$ to $10^{-9}$ ) were added to Vero cells in 96-well plates, and eight 
wells were used at each dilution. The 96-well plates were incubated for 7 days at $37^{\circ} \mathrm{C}$, and the $\mathrm{TCID}_{50}$ values were measured by determining CPE. The $\mathrm{TCID}_{50}$ values were calculated by the method of Reed-Muench [27].

\section{Determination of $\mathrm{LD}_{50}$ in mice}

To determine the $50 \%$ lethal dose $\left(\mathrm{LD}_{50}\right)$, specific-pathogen-free, two-day-old BALB/c mice were inoculated intraperitoneally with $100 \mu \mathrm{l}$ of serially diluted $\mathrm{Hn} 2$ virus. The survival of the mice was monitored daily, and the $\mathrm{LD}_{50}$ was calculated as described by Reed-Muench [27].

\section{Production of monoclonal antibody}

The purified $\mathrm{Hn} 2$ virus was inactivated by heating at $56^{\circ} \mathrm{C}$ for 30 min. Groups of 5 adult (4 weeks old) female BALB/ c mice were immunized intraperitoneally in a $50 \%$ emulsion of Freund's complete adjuvant with $10 \mu \mathrm{g}$ heat-inactivated EV71 virus. Two booster doses, again in 50\% emulsion with Freund's incomplete adjuvant, were given at 2 weeks intervals. Two weeks after the last immunization, blood samples were obtained from the tail and tested by enzyme-linked immunosorbent assay (ELISA) using purified $\mathrm{Hn} 2$ virus as antigen. The fusion of spleen cells with mouse myeloma cell was done as described [28]. For the production of MAbs, BALB/c mice (4-6 weeks old) were injected intraperitoneally with $10^{6}$ hybridoma cells per mouse. Ten days later, the ascitic fluid was drained by using an 18-gauge needle. The ascites were centrifuged at $1,000 \mathrm{~g}$ for $10 \mathrm{~min}$ to remove cells, MAbs were purified from collected supernatants by precipitation with $50 \%$ saturated ammonium sulfate $(\mathrm{pH} \mathrm{7.0)}$ and dialysised against $0.04 \mathrm{M}$ phosphate buffer ( $\mathrm{pH}$ 6.8). The MAbs were further purified by using protein A agarose columns (Bio-Rad Laboratories).

\section{In vitro neutralizing antibody assay}

The presence of neutralizing MAbs was determined by in vitro assay in Vero cell. Monoclonal antibody samples were incubated at $56^{\circ} \mathrm{C}$ for $30 \mathrm{~min}$ to inactivate the complement. Briefly, $50 \mu \mathrm{l}$ of two-fold antibody dilutions were mixed with equal volumes of $100 \mathrm{TCID}_{50}$ of $\mathrm{Hn} 2$ virus, and then the mixture was added to monolayers of Vero cells in 96-well plates. All serum samples were tested in 8 wells. After 3 days of growth, the titer of neutralizing antibody was read as the highest dilution that gave complete protection from CPE.

\section{Peptide ELISA assay}

Synthetic peptides spanning the entire sequence of the Hn2 VP1 protein (GenBank accession no. GQ994992) were synthesized by Invitrogen Company (Beijing, P.R.China). Each peptide contains 10 amino acid residues and the levels of antibody reactive to each synthetic peptide were measured by ELISA assay. The 96-well plates were coated overnight at $4^{\circ} \mathrm{C}$ with $50 \mu \mathrm{l}$ of $0.1 \mathrm{M}$ carbonate buffer (pH 9.6) containing $500 \mathrm{ng}$ of synthetic peptide or E.coli expressed EV71 VP1 protein (supplied by Professor Hanzhong Wang, Wuhan Institute of Virology, Chinese Academy of Science). After blocking with 2\% bovine serum albumin (BSA), the plates were incubated with $50 \mu \mathrm{l}$ of $\mathrm{MAb}$ at the indicated dilutions at $37^{\circ} \mathrm{C}$ for 1 $\mathrm{h}$ and then washed three times with phosphate buffered saline (PBS) containing $0.1 \%$ Tween 20. Horseradish peroxidase-conjugated goat anti-mouse IgG antibody (SantaCruze, USA) was used as secondary antibody at $37^{\circ} \mathrm{C}$ for $1 \mathrm{~h}$ and the reaction was developed by TMB substrate (KPL, Gaithersburg, MD). The absorbance at $450 \mathrm{~nm}$ was measured by an ELISA plate reader (Tecan Sunrise, USA). Each assay was performed three times independently.

\section{Passive protection test in mice}

Two-day-old BALB/c mice were obtained from the Laboratory Animal Center, Academy of Military Medical Sciences, Beijing. Institutional guidelines for animal care and use were followed throughout the experiments. Groups of mice were injected intraperitoneally with 100 $\mu \mathrm{l}\left(100 \mathrm{LD}_{50}\right)$ of $\mathrm{Hn} 2$ virus, followed $24 \mathrm{~h}$ later by $100 \mu \mathrm{l}$ of heat-treated $\left(56^{\circ} \mathrm{C}, 30 \mathrm{~min}\right) \mathrm{MAb}$. Mice in the control group were injected with the same volume of normal mice serum. The mice were monitored for clinical symptoms, paralysis and death up to day 21 post-inoculation.

\section{Computational analysis of VP1 sequence}

Nucleotide sequence and the amino acid sequences were edited and aligned using CLC Main Workbench 5.5 software. The antigenicity of the Hn2 VP1 protein were analyzed using the method of Kolaskar and Tongaonkar [16], and antigen epitopes were predicted using the amino acid sequences of the Hn2 VP1 as query sequences in the Web: http://www.mifoundation.org.

\section{Competing interests}

The authors declare that they have no competing interests.

\section{Authors' contributions}

GHC is the principal investigator and draft the manuscript; YJL, XYW and BYS carried out the the animal test and immunoassays of the MAbs. $L L$ participated in the sequence analysis. QYZ participated in its design and coordination of the study. All authors read and approved the final manuscript.

\section{Acknowledgements}

This work is supported by Research Grant SKLPBS0919 from State Key Laboratory of Pathogen and Biosecurity.

We thank Prof. Stuart Siddell for help in editing.

\section{Author Details}

State Key Laboratory of Pathogen and Biosecurity, Beijing Institute of Microbiology and Epidemiology, 20 Dongda Street, Fengtai District, Beijing, 100071, PR China

Received: 6 April 2010 Accepted: 26 May 2010

Published: 26 May 2010 


\section{References}

1. Schmidt NJ, Lennette $\mathrm{EH}, \mathrm{Ho} H \mathrm{H}$ : An apparently new enterovirus isolated from patients with disease of the central nervous system. $J$ Infect Dis 1974, 129:304-309.

2. Hagiwara A, Yoneyama T, Takami S, Hashimoto I: Genetic and phenotypic characteristics of enterovirus 71 isolates from patients with encephalitis and with hand, foot and mouth disease associated with enterovirus 71 infection. Arch Virol 1984, 79:273-283.

3. Mizuta K, Abiko C, Murata T, Matsuzaki Y, Itagaki T, Sanjoh K, Sakamoto M, Hongo S, Murayama S, Hayasaka K: Frequent importation of Enterovirus 71 from surrounding countries into the local community of Yamagata, Japan, between 1998 and 2003. J Clin Microbio 2005, 43:6171-6175.

4. Chumakov M, Voroshilova M, Shindarov L, Lavrova I, Gracheva L, Koroleva G: Enterovirus 71 isolated from cases of epidemic poliomyelitis-like disease in Bulgaria. Arch Virol 1979, 60:329-340.

5. Abubakar S, Chee HY, Shafee N, Chua KB, Lam SK: Molecular detection of enteroviruses from an outbreak of hand, foot and mouth disease in Malaysia in 1997. Scand J Infect Dis 1999, 31:331-335.

6. Ho M, Chen ER, Hsu KH, Twu SJ, Chen KT, Tsai SF: An epidemic of enterovirus 71 infection in Taiwan. New Engl J Med 1999, 341:929-935.

7. Li RQ, Chen LJ, Wang YM, Zhang HR, He X: Genetic characteristics of enterovirus 71 isolated in Beijing, 2006-2008. Zhonghua Liu Xing Bing Xue Za Zhi 2009, 30:45-49. Chinese

8. Lin L, He YQ, Hong Y, Zhu JP: Genetic Characteristics of Human Enterovirus 71 and Coxsackievirus A16 Circulating from 1999 to 2004 in Shenzhen, People's Republic of China. J Clin Microbio 2005, 43:3835-3839.

9. Chang GH, Lin L, Luo YJ, Cai LJ, Wu XY, Xu HM, Zhu QY: Sequence analysis of six enterovirus 71 strains with different virulences in humans. Virus Res 2010, 151:66-73.

10. Da Silva EE, Winkler MT, Pallansch MA: Role of enterovirus 71 in acute flaccid paralysis after the eradication of poliovirus in Brazil. Emerg Infect Dis 1996, 2:231-233.

11. Brown BA, Pallansch MA: Complete nucleotide sequence of enterovirus 71 is distinct from poliovirus. Virus Res 1995, 39:195-205

12. Foo DGW, Alonso S, Phoon MC, Ramachandran NP, Chow VTK, Poh CL: Identification of neutralizing linear epitopes from the VP1 capsid protein of enterovirus 71 using synthetic peptides. Virus Res 2007 125:61-68.

13. Guang DM, Foo W, Alonso S, Chow VTK, Poh CL: Passive protection against lethal enterovirus 71 infection in newborn mice by neutralizing antibodies elicited by a synthetic peptide. Microbes Infect 2007 9:1299-1306.

14. Chiu CH, Chu C, He CC, Lin TY: Protection of neonatal mice from letha enterovirus 71 infection by maternal immunization with attenuated Salmonella enterica serovar Typhimurium expressing VP1 of enterovirus 71. Microbes Infect 2006, 8:1-8.

15. Wu CN, Lin YC, Fann C, Liao NS, Shih SR, Ho MS: Protection against enterovirus 71 infection in newborn mice by passive immunization with subunit VP1 vaccines and inactivated virus. Vaccine 2001, 20:895-904.

16. Kolaskar AS, Tongaonkar PC: A semi-empirical method for prediction of antigenic determinants on protein antigens. FEBS Lett 1990, 276:172-174.

17. McMinn PC: An overview of the evolution of Enterovirus 71 and its clinical and public health significance. FEMS Microbiol Rev 2002, 26:91-107.

18. Blomberg J, Lycke E, Ahlfors K, Johnsson T, Wolontis S, Von Ziepe Gl: New enterovirus type associated with epidemic of aseptic menigitis and: or hand, foot, and mouth disease. Lancet 1974, 2:112-119.

19. Huang CC, Liu CC, Chang YC, Chen CY, Wang ST, Yeh TF: Neurologic complications in children with enterovirus 71 infection. N Engl J Med 1999, 341:936-942.

20. Kimura-Kuroda J, Yasui K: Protection of mice against Japanese encephalitis virus by passive administration with monoclonal antibodies. J Immunol 1988, 141:3606-3610.

21. Huang YC, Lin TY, Lin YJ, Lien RI, Chou YH: Prophylaxis of intravenous immunoglobulin and acyclovir in perinatal varicella. Eur J Pediatr 2001, 160:91-94.

22. Geller TJ, Condie D: A case of protracted coxsackie virus meningoencephalitis in a marginally immunodeficient child treated successfully with intravenous immunoglobulin. J Neurol Sci 1995, 129:131-133.

23. Thomas AAM, Brioen P, Boye A: A monoclonal antibody that neutralizes poliovirus by cross-linking virions. J of Virol 1985, 54:7-13.

24. Smith TJ, Olson NH, Cheng RH, Chase ES, Baker TS: Structure of a human rhinovirus-bivalently bound antibody complex: implications for viral neutralization and antibody flexibility. Proceedings of the National Academy of Sciences. USA 1993, 90:7015-7018.

25. Lal SK, Kumar P, Yeo WM, Kar-Roy A, Chow VT: The VP1 protein of human Enterovirus 71 self-associates via an interaction domain spanning amino acids 66-297. J Med Virol 2006, 78:582-590.

26. Tan CS, Cardosa MJ: High-titred neutralizing antibodies to human enterovirus 71 preferentially bind to the $\mathrm{N}$-terminal portion of the capsid protein VP1. Arch Virol 2007, 152:1069-1073.

27. Reed $\sqcup$, Muench $\mathrm{H}$ : A simple method of estimating 50 percent endpoints. Am J Hyg 1938, 27:493-497.

28. Kohler G, Milstein C: Continuous cultures of fused cells secreting antibody of predefined specificity. Nature 1975, 256:495-497.

doi: 10.1186/1743-422X-7-106

Cite this article as: Chang et al., Monoclonal antibody induced with inac tived EV71-Hn2 virus protects mice against lethal EV71-Hn2 virus infection Virology Journal 2010, 7:106

\section{Submit your next manuscript to BioMed Central and take full advantage of:}

- Convenient online submission

- Thorough peer review

- No space constraints or color figure charges

- Immediate publication on acceptance

- Inclusion in PubMed, CAS, Scopus and Google Scholar

- Research which is freely available for redistribution
C Biomed Central 